\title{
LÓGICA, CIENCIA Y EXPERIENCIA EN LA VALORACIÓN DE LA PRUEBA*
}

\author{
LOGIC, SCIENCE AND EXPERIENCE IN THE ANALYSIS \\ OF EVIDENCE
}

\author{
Rodrigo Coloma Correa** \\ Claudio Agüero San Juan ***
}

\begin{abstract}
RESUMEN: El propósito de este artículo es aclarar lo que cabe esperar de los conocimientos científicamente afianzados, de las máximas de la experiencia y de los principios de la lógica, en el contexto de la valoración de la prueba conforme a la sana crítica. Para tales efectos, en la primera mitad del texto se realiza un ejercicio de depuración conceptual, entendiéndose, por una parte, que los principios de la lógica sirven para resolver problemas lingüístico-interpretativos; y por la otra que los conocimientos científicamente afianzados y las máximas de la experiencia se utilizan para satisfacer requerimientos epistémico-culturales. En la segunda mitad del texto se abordan problemas de jerarquización y de coordinación entre generalizaciones extraíbles desde la lógica, la ciencia y la experiencia.
\end{abstract}

Palabras clave: Conocimientos científicamente afianzados, lógica, jueces, máximas de la experiencia, sana crítica.

ABSTRACT: The aim of this article is to clarify what is expected of scientific knowledge, experiential knowledge and logic principles, in the context of the analysis of evidence according to sound criticism. For this purpose, in the first part of the text it is offered a conceptual framework, in the understanding that the logic principles are used to solve linguistic-interpretative problems and, in turn, that scientific and experiential knowledge are used to satisfy epistemic-cultural requirements. The second part deals with the problems of hierarchy and coordination between logical, scientific, and experiential generalizations.

Key words: Scientifically supported knowledge, logic, judges, experiential knowledge, sound criticism.

\footnotetext{
Este trabajo corresponde a resultados del Proyecto financiado por el Fondo Nacional de Desarrollo Científico y Tecnológico, FONDECYT No 1110409 "La construcción de lo probado en los procesos judiciales. Vaivenes entre la ciencia, la lógica, el sentido común y la íntima convicción del juzgador".

" Profesor de la Facultad de Derecho de la Universidad Alberto Hurtado. Correo electrónico: rcoloma@uahurtado.cl. Licenciado en Derecho, Pontificia Universidad Católica de Chile; Doctor en Derecho, Universidad Carlos III de Madrid; Presidente de la Sociedad Chilena de Filosofía Jurídica y Social.

... Profesor de la Facultad de Derecho de la Universidad Alberto Hurtado. Correo electrónico: caguero@uahurtado.cl. Licenciado en Derecho, Universidad Católica de Temuco; Máster en Derecho, Universidad degli Studi di Genova; Doctor en Ciencias Humanas Universidad Austral de Chile.
} 


\section{LAS EXPECTATIVAS QUE NO HAN SIDO SATISFECHAS POR LOS PRINCIPIOS DE LA LÓGICA (PL), LOS CONOCIMIENTOS CIENTÍFICAMENTE AFIANZADOS (CCA) Y LAS MÁXIMAS DE LA EXPERIENCIA (ME) ${ }^{1}$}

\subsection{INTRODUCCIÓN}

Uno de los indicadores más potentes de la madurez alcanzada por una disciplina está constituido por su capacidad para delimitar lo que de ella puede esperarse.

Los juristas, de forma oblicua, han venido comunicando desde hace bastante tiempo que su experticia debe situarse en el campo de la determinación de la validez de textos con pretensiones normativas; de la atribución de significados de disposiciones normativas y, de la reconstrucción económica de sus saberes y métodos, a través de la formulación y depuración de teorías. Esta opción por el mundo de las normas (o de las palabras) ha implicado una participación temerosa de los juristas en el mundo de los hechos. Así, por ejemplo, los saberes y métodos que los peritos despliegan cuando se les invita a participar en los procesos judiciales, resultan difíciles de comprender y controvertir, tanto para los jueces como para los abogados, pasando a constituir, en algunos casos, auténticos argumentos de autoridad. ${ }^{2}$ En concordancia con lo señalado, la cultura jurídica ha consensuado un rechazo a que la valoración de la prueba sea un asunto que (únicamente) se haga depender de la aplicación de normas legisladas o de las preferencias de los jueces (expertos en Derecho).

\subsection{LA ADHESIÓN AL MODELO DE LA SANA CRÍTICA}

El retroceso experimentado por la prueba tasada e íntima convicción en varios de nuestros procedimientos, por una parte, y la irrupción de la sana crítica, por la otra, obedece a una decisión legislativa que es consistente con la comprensión de que el problema social de fijar el pasado ${ }^{3}$ debe resolverse usando conocimientos públicos. La sana crítica se asocia a un conjunto de patrones de decisión -los PL, las ME y los CCA- que en distinta medida y modo resultan accesibles a un universo amplio de los miembros del grupo social.

La flexibilidad de la sana crítica la erige, prima facie, como una alternativa idónea para superar los reproches que aquejan a la prueba tasada (excesiva sujeción judicial) y a la íntima convicción (excesiva libertad judicial). La sana crítica obliga a los jueces a tomar

\footnotetext{
1 Un borrador de este texto fue discutido en el Seminario 3 de la Universidad Alberto Hurtado. Los comentarios estuvieron a cargo de Cristóbal Joannon L. Agradecemos las agudas observaciones que nos fueron planteadas por todos los participantes. Los errores que perduran, huelga decirlo, son responsabilidad nuestra. Asimismo, agradecemos a Victoria Martínez P. la minuciosa revisión de este texto cuidando el cumplimiento de los requisitos exigidos para su publicación.

2 Otra manifestación de esto la constituyen formas procedimentales que para fijar el pasado recurren a no especialistas en asuntos jurídicos. En nuestro sistema jurídico, como se sabe, la presencia de jurados resulta un fenómeno extraño. Sin embargo, en algunos asuntos propios de derecho regulatorio, se ha ido confiando progresivamente la toma de decisiones a expertos en otras disciplinas (Véase, por ejemplo, el Panel de Expertos de la Ley General de Servicios Eléctricos, en título VI de la ley 19.940).

3 Por cierto, dependiendo el tipo de asuntos, en un proceso judicial podrá requerirse fijar el presente y el futuro, suponiendo esto último como una predicción o una proyección.
} 
decisiones usando generalizaciones ${ }^{4}$ validadas fuera del sistema jurídico en razón de sus propiedades epistémico-culturales. ${ }^{5} \mathrm{Al}$ mismo tiempo, la sana crítica permite que los jueces usen sus preferencias en los casos en donde las generalizaciones no operan, o bien, su seguimiento conduce a un resultado difuso. ${ }^{6} \mathrm{El}$ atractivo de la sana crítica proviene, entonces, de una mezcla de libertad y de sujeción en la valoración de las pruebas disponibles en un juicio, la cual se espera reduzca los falsos positivos y los falsos negativos ${ }^{7}$ que la aplicación de sistemas de pura libertad o de pura sujeción tienden a favorecer.

La sana crítica -en su dimensión de sujeción- prohíbe a los jueces recurrir a conocimientos privados provenientes de experiencias individuales, si se trata de situaciones en las que los CCA y las ME están en condiciones de ofrecer respuestas a los enigmas planteados en un juicio. ${ }^{8}$ El modelo de la sana crítica estimula, de esta manera, la aplicación de generalizaciones que cuentan con mayor legitimación que las creencias personales de los jueces, a los efectos de representar el mundo. ${ }^{9}$ La sana crítica -en su dimensión de libertad- apunta a que es absurdo reducir cualquier manifestación de conducta humana a una estructura que correlaciona anticipadamente un caso con una solución, esto es: «si se demuestra la existencia de un determinado estado de cosas, estaremos autorizados para contar con que otro estado de cosas (necesariamente/probablemente) se ha producido». ${ }^{10}$ Esta constatación ha llevado a que la decisión del legislador en orden a autoconstreñir su potestad de dictar reglas sobre cómo deben valorarse las pruebas -o de reenviar a otros sistemas de producción de conocimientos en asuntos a los que estos no pueden dar respuestas- se entienda como una estrategia que aminora los potenciales errores en que podría incurrirse en las sentencias. Así, el modelo de la sana crítica evita la errónea aplicación de generalizaciones que carecen de legitimación epistémico-cultural, dando espacio para que las creencias de los jueces (todas las cosas consideradas) sean las que provean de respuestas.

\footnotetext{
4 Entendemos por generalización "una proposición general con pretensiones de verdad [o corrección] que es usada implícita o explícitamente para argumentar que una conclusión ha sido bien establecida.” ANDERSON, Schum y Twining (2005) p. 383. El paréntesis es un añadido nuestro y busca ampliar el uso de la expresión a los PL.

5 En este sentido, supera a la prueba tasada que somete al juez a las preferencias del legislador que no cuenta con credenciales epistémico culturales, sino solamente de carácter políticas.

6 En ese sentido, supera a la íntima convicción dado que reconoce a los jueces libertad solo en espacios donde lo opinable constituye una opción legítima para la valoración de la prueba.

7 Falsos positivos (desconocer un caso cuando efectivamente ocurre), o falsos negativos (exigir el reconocimiento de un caso cuando este, en realidad, no ha ocurrido).

8 Un texto clásico al respecto que llama la atención sobre los errores a que nos conducen principios heurísticos a los que usualmente recurrimos es TVERSKY y KAHNEMAN (2012).

9 Coloma (2012) pp. 207-228.

${ }^{10}$ El costo que se estaba asumiendo con sistemas de prueba tasada que proveían una ilusión de certeza parecían muy altos. Así, por ejemplo, si la prueba de un hecho se hacía depender de lo que dijeran dos testigos contestes se estaba logrando certidumbre epistémica a costa de envilecerla. En pocas palabras, lo que se estaba consagrando era que lo que decían dos testigos contestes no resultaba derrotable, aun cuando se sabía que era posible que pudieran estar mintiendo o bien que sus recuerdos fueran poco fiables. Los testigos adquirían de esa manera un poder enorme que se trataba de atemperar con la amenaza de sanciones (falso testimonio) que raramente eran aplicadas.
} 
A lo anterior debe añadirse que la libertad para valorar la prueba no implica que cualquier proposición esté en condiciones de ser incorporada en una sentencia, bajo el supuesto de que refleje las preferencias de los juzgadores. Existen restricciones lingüísticointerpretativas por la vía de que los tribunales siempre deben ceñirse a exigencias mínimas de relevancia, aceptabilidad, normalidad, fuerza ${ }^{11}$ y refutabilidad, las cuales son constituidas mediante los PL.

\subsection{LAS PROMESAS INCUMPLIDAS DE LA SANA CRÍTICA}

Los jueces repiten ciertas fórmulas, aun cuando de ello no se deriven consecuencias para la decisión judicial. Una de ellas reza más o menos así "Que valorados los medios de prueba con libertad y no contradiciendo los PL, los CCA y las ME se da por probado que...» A contrario de lo que podría espontáneamente pensarse, el uso de este estribillo no se traduce en ninguna consecuencia jurídica; en otras palabras, no blinda a la decisión y, a la inversa, su supresión no la hace, ipso facto, impugnable. ${ }^{12}$

El uso de frases y palabras sacramentales es un problema en la medida en que los miembros de la comunidad jurídica creen que con su enunciación 'inmediatamente' la decisión pasa a satisfacer las exigencias de la sana crítica. No es evidente, sin embargo, que los jueces y abogados le atribuyan (o nieguen) tal poder constitutivo a la frase citada. Lo que sí se puede afirmar es que su uso irreflexivo deja de manifiesto que jueces y abogados no están seguros qué implica valorar la prueba con sujeción a los PL, las ME y los CCA.

Las generalizaciones asociadas a los CCA y a las ME a menudo son difusas y no se encuentran institucionalizadas. Los PL, por su parte, bajo la concepción que entiende que solo aseguran el respeto de un baremo mínimo en el uso del lenguaje -que dicho sea de paso: difícilmente un juez en su sano juicio dejará de seguir- resultan siendo invocados de modo asistemático y poco reflexivo. Ambas dificultades impiden que los jueces cuenten con heurísticas (formas de procesamiento de información) uniformes para valorar la prue$\mathrm{ba}^{13}$. Estas dificultades se acentúan en los casos no rutinarios, ya que la evanescencia de las generalizaciones que pueden extraerse de la experiencia y, en menor medida, de la ciencia,

\footnotetext{
${ }_{11}$ Apostel (2007) pp. 129-137.

${ }_{12}$ Hay, por cierto otras situaciones en que la valoración de la prueba sin hacer explícito el marco dentro del cual se mueve opera efectivamente conforme a lo esperado. Así, por ejemplo, en la siguiente sentencia se dice: "Que se desestima la declaración de la acusada en estrados, en cuanto a que puso al menor a un metro o un metro y medio del brasero y que el fuego, estaba prácticamente extinguiéndose, ya que tal versión es incompatible con las lesiones ocasionadas a la víctima, para cuyo efecto necesariamente debió existir una fuente calórica de consideración y una corta distancia entre ésta y la zona afectada" Ministerio Público con Lorena Maldonado (2010).

${ }_{13}$ Esto último dificulta, por ejemplo, la institucionalización de un sistema de recursos que permita hacer frente a sentencias judiciales defectuosas (y, en general, debilita la crítica sana ante decisiones desviadas). La idea de corrección (débil o fuerte) que se asocia a la sana crítica implica que si son entendidas como reglas y no meras sugerencias, debiese existir la posibilidad de revisar decisiones acerca de lo que se da por probado en un caso si es que no satisface la idea respectiva de corrección (como también, la posibilidad de realizar críticas justificadas).
} 
conduce a que, habitualmente, al valorar el conjunto de los medios de prueba disponibles los jueces privilegien una aproximación holística por sobre una de tipo analítico. ${ }^{14}$

La escasa presión normativa del modelo de la sana crítica se vincula a que jueces y abogados no han resuelto satisfactoriamente distintos problemas. Una muestra de ello sería la siguiente: i) es insoslayable que los CCA suponen una separación entre los conocimientos de los especialistas y de los jueces, careciendo estos últimos de control respecto de lo que dicen los primeros; ii) el conocimiento que surge de la experiencia social (ME) es poroso y plural; y iii) el control de las relaciones entre los enunciados que forman parte de las propuestas interpretativas presentadas por los abogados exige decidir en un escenario de incertidumbre. ${ }^{15}$ Respecto al primer problema, es preciso tener en cuenta que la velocidad de los avances científicos y tecnológicos y su complejidad han lesionado las pretensiones del modelo de la sana crítica. La rapidez en los cambios ha implicado que los CCA resultan efímeros. Por su parte, la complejidad de los saberes ha redundado en que solo los especialistas estarán en condiciones de detectar los fallos en la aplicación de procedimientos y en la transmisión de saberes en casos concretos. El riesgo de errar el juicio que califica a un conocimiento como 'científicamente afianzado' se incrementa aún más si tenemos en cuenta de que entre los especialistas hay desacuerdos, que hay escuelas rivales y que hay disciplinas que luchan por el reconocimiento de un estatus de cientificidad. ${ }^{16}$

Una aguda reflexión sobre el problema de la escasa controlabilidad de lo que se presenta como CCA y de las propuestas rivales puede verse en el siguiente fragmento de una sentencia dictada por la Corte de Apelaciones de Valdivia: "Que excede con mucho el marco de actuación de un Tribunal de Justicia realizar, en una sentencia judicial, una evaluación de las posibilidades terapéuticas de la medicina conocida como "alternativa", respecto de aquellas ofrecidas por la medicina tradicional o alópata, ni en abstracto ni en el caso concreto de la leucemia y del cáncer testicular que afecta al menor Robynson Gómez Noa. Tampoco, una determinación de cuál de las posibilidades ofrecidas por la medicina alópata resulte más conveniente, si aquella de los médicos del Hospital Base en Valdivia, o la del médico cirujano tratante en Santiago, Sr. Silva Jaramillo. Esencialmente, porque esas son evaluaciones que ni siquiera quienes tienen la experticia científica pueden hacer con una razonable dosis de seguridad. No es, por tanto, una evaluación de esa clase la que permitirá resolver la controversia planteada a esta Corte». ${ }^{17}$

\footnotetext{
${ }_{14}$ En rigor la borrosidad (o vaguedad conceptual) es un problema que afecta tanto a la "sana crítica" como a la "racionalidad". Sobre esta última véase VoN WRIGHT (1993) p.172. En lo que sigue, la borrosidad que aquí preocupa es la que refiere a la sana crítica.

15 Por cierto, hay también otra clase de problemas que no serán sino tangencialmente abordados, como es el caso de las lagunas de conocimientos de jueces y abogados respecto del discurso científico.

16 No se trata, por cierto, que tengamos una peor ciencia que en el pasado. De hecho, contamos con buenas razones para sostener que la ciencia actual permite resolver de mejor manera que antaño, los mismos o nuevos enigmas (por ejemplo, diagnóstico y tratamiento de enfermedades, transporte aéreo, etc.) Lo que aquí interesa apunta a que la consolidación de los conocimientos científicos es un asunto que se hace más difícil de resolver en razón del escenario de creciente complejidad y de caducidad al cual nos enfrentamos. Sobre estos problemas existe abundante literatura en otros países. Como una pequeña muestra considérese HAACK (2007), Huber (2011).

17 Robynson Gómez Noa (1999).
} 
Respecto al segundo problema, el fracaso de la sana crítica se relaciona con la multiculturalidad de nuestras sociedades. El sentido de las ME es posibilitar el uso de conocimientos que surgen a partir de las vivencias de quienes pertenecen a la misma cultura. Es decir, a partir de cómo los miembros de una comunidad interpretan ciertos acontecimientos de la vida social. Ocurre que cuando los miembros de una comunidad sincretizan prácticas sociales por la influencia de otros grupos, la cultura se vuelve porosa ${ }^{18} \mathrm{y}$, entonces, las directrices que se infieren a partir de las experiencias sociales comienzan también a adquirir porosidad y pluralidad. Usar las ME para inferir cuáles son las prácticas frecuentes en algunos subgrupos sociales es riesgoso. ${ }^{19}$ Por cierto, esto puede provocar errores al no considerar suficientemente los rasgos que acercan y alejan a un sujeto de una determinada práctica o creencia social.

A continuación, se introduce un fragmento de sentencia que amplía ciertas formas de operar en un subgrupo, aun cuando hay buenas razones para sostener que es muy minoritario (quienes no se someten a un horario de trabajo riguroso, respecto de los que sí lo hacen): «(...) considerando además la falta de precisión en cuanto a la hora de llegada del hijo al San Francisco de Mostazal, ya que mencionó, como se dijo, que fue alrededor de las 18:30 a 19:00 horas, cálculo que hizo, según lo afirmó en la audiencia, en base a que ella trabaja hasta las 18:00 horas -no refiere haber mirado el reloj- y que cuando llegó a su domicilio éste ya estaba en la casa, de suyo, según los principios de la lógica y las máximas de la experiencia, no es de normal ocurrencia irse del lugar de trabajo, todos los días, exactamente a la misma hora permitida y establecida como de salida». ${ }^{20}$

En otros casos, el temor hacia las excepciones de generalizaciones propias de las ME pueden llevar a no utilizarlas produciendo algunos resultados que se alejan de la manera en que se da normalmente la interacción social. Esto es lo que se critica del accionar del tribunal de instancia por parte de la Corte de Apelaciones. "La lógica y el conocimiento empírico llevan a concluir necesariamente que quien introduce en una tienda alguna especie en un bolso particular, antes de pagar por ella, obviamente es porque se está apoderando de ella sin la voluntad de su dueño, pues de lo contrario pasaría por caja y la pagaría, desde que el giro del establecimiento es la venta de ropa y no su donación». ${ }^{21}$

En cuanto al tercer problema, el fracaso de la sana crítica se asocia a la coexistencia de varios tipos de lógicas. Probablemente, por el atractivo que para los juristas representan los sistemas de enunciados completos y coherentes ellos se declaran comprometidos con la lógica clásica para modelar el razonamiento jurídico, aunque su utilidad resulta mínima

\footnotetext{
18 "De esto se desprende que aunque necesitamos significados culturales, no requerimos marcos culturales homogéneos. Necesitamos entender nuestras elecciones en el contexto en que estas tengan sentido, pero no necesitamos un único contexto para estructurar todas nuestras elecciones. Porque no necesitamos un marco cultural homogéneo o la integridad de una determinado catálogo de significados, ninguno de nosotros necesita estar inmerso en una de esas comunidades de pequeña escala que, de acuerdo con Kymlicka y otros, son las únicas capaces de asegurar la integridad y la homogeneidad”. WALDRON (1996) pp. 105-108.

19 Un texto que aborda este problema y que insta al uso del cálculo probabilístico, en la medida que resulte posible es Schauer (2003), véase especialmente, pp. 55-78.

20 Ministerio Público con Inti Ramírez Basic (2007).

21 Ministerio Público con Nicole Parra (2012).
} 
al decidir un caso judicial. El problema es que las lógicas no aristotélicas son difíciles de dominar impidiendo que los abogados y jueces las integren a su modo de pensar de los problemas jurídicos.

En la práctica judicial suele identificarse la falta de sujeción a los PL con la fragilidad de las conexiones entre los enunciados que dan cuenta de la prueba disponible y los utilizados para dar cuenta representar los acontecimientos probados. Esta forma de operar olvida que las categorías propias de la lógica clásica no controlan el contenido de los enunciados y que hay reglas de gestión de incertidumbre que no dependen de esta. En otras palabras, los jueces aciertan cuando ven afectados los PL si la estructura informativa carece de consistencia, pero yerran cuando tratan de decidir problemas invocando la lógica clásica.

Un ejemplo de aquello sería el que sigue: «Que, el examen de la prueba rendida durante el juicio oral, según resumen efectuado en el fallo y los argumentos que dan pábulo a la defensa para recurrir de nulidad, conduce a esta Corte a establecer que los sentenciadores no vertieron los argumentos necesarios para dirimir, a lo menos, cinco aspectos relevantes concernientes a la participación e identificación de quien habría sido el autor de los disparos (...). Que, las omisiones destacadas en el razonamiento anterior, atentan al principio de la lógica, denominado "de la razón suficiente", el que se enuncia como "todo objeto debe tener una razón suficiente que lo explique" o en forma negativa "ninguna enunciación puede ser verdadera sin que haya una razón suficiente para que sea así y no de otro modo».22

En rigor el problema abordado se relaciona con un uso inadecuado del estándar de prueba exigible -en este caso- en materia penal. La prueba disponible apuntaba a hacerse cargo del problema que representaba la identificación del autor de los disparos, pero la ambigüedad de las declaraciones llevaba a que hubiese dudas razonables acerca de quién era este. Al declarar el tribunal que en el caso concreto estaba probado que el acusado había sido el autor de la conducta reprochada, a pesar que la prueba era ambigua, no se vulneraba stricto sensu el principio de razón suficiente. ${ }^{23}$

Los tres problemas señalados son un obstáculo para demostrar que las soluciones ofrecidas por el modelo de la sana crítica son 'indudablemente mejores' que las soluciones que suministran los modelos de prueba tasada e íntima convicción. ${ }^{24}$ En otras palabras, la sana crítica no ha cumplido con las expectativas que en ella se han cifrado, pues no ha impactado de manera determinante en la manera de razonar de los jueces. Ellos no parecen hacer algo sustancialmente diferente a lo podrían hacer si el modelo adoptado fuese la íntima convicción o, incluso, el de prueba tasada algo morigerado.

\footnotetext{
22 Ministerio Público con Mans (2012).

23 El principio de razón suficiente se habría visto afectado si por ejemplo, el tribunal hubiera señalado que las balas que se alojaron en el cuerpo de la víctima aparecieron por generación espontánea, sin que se hubiere realizado ningún proceso del exterior conducente a que ello ocurriera.

24 En rigor, en los sistemas de prueba tasada no se elimina totalmente la discrecionalidad de los jueces, ni en los sistemas de íntima convicción los jueces son totalmente libres para valorar la prueba según se les plazca (hay, al menos, un control social).
} 


\section{2. ¿QUÉ CABE ESPERAR DE LOS PL, CCA Y ME?}

\subsection{INTRODUCCIÓN}

La valoración de la prueba tiene una dimensión que podría llamarse epistémicocultural y otra, que podría denominarse lingüístico-interpretativa. Un primer asunto que atañe a la dimensión epistémico-cultural se refiere a que la valoración de la prueba supone decidir sobre la fuerza de los datos que se sitúan en la base del razonamiento probatorio, esto es los medios de prueba. Los jueces deben decidir si un testigo es creíble a los efectos de reconocer que lo dicho es soporte de un evento probado. ${ }^{25}$ En el modelo de la sana crítica para dirimir si una pieza de información cuenta o no con suficiente validez para la generación de conocimientos, debe realizarse un juicio (valoración) de si aquella se encuentra epistémicamente o culturalmente reconocida como soporte válido de un discurso no ficcional. Un segundo asunto que se resuelve en conformidad a criterios validados a nivel epistémico o cultural refiere a las inferencias que pueden llevarse a cabo a partir de las pruebas disponibles. La cuestión es determinar si desde un conjunto de datos dados, es posible arribar a un conjunto de conclusiones válidas usando generalizaciones -que podrían ir desde patrones legitimados en una comunidad especializada hasta conocimientos populares (folk)- sobre cómo ocurren las cosas.

Esto representa la dimensión más clara de lo que significa probar. En palabras de J. H. Wigmore "Prueba es siempre un término relativo. Significa una relación entre dos hechos, el factum probandum, o proposición a ser probada, y el factum probans, o material que prueba la proposición. El primero es necesariamente hipotético; el último es presentado como real para el propósito de convencer que el último también es real”. ${ }^{26}$

El asunto no termina aquí, pues la valoración de la prueba tiene una dimensión lingüístico-interpretativa que determina cuándo puede válidamente en el contexto de una comunidad sostenerse que un texto (oral o escrito) informa sobre un evento cuya ocurrencia se estima como probada.

\subsection{LA DETERMINACIÓN DEL ESTATUS EPISTÉMICO-CULTURAL DE LA INFORMACIÓN Y EL} CONTROL LINGÜÍSTICO-INTERPRETATIVO DE LA SENTENCIA COMO FUNCIONES DE LOS PL, LOS CCA Y LAS ME

En comparación con la forma en que operan otros sistemas de procesamiento de información (por ejemplo, diagnóstico médico), el esfuerzo que representa comunicar en un texto la actividad de justificar la decisión judicial y su contenido corre el riesgo de que se le considere como un despilfarro de recursos. ${ }^{27} \mathrm{La}$ comunicación de la justificación posibilita satisfacer las expectativas del auditorio sobre el resultado del proceso de valoración de la prueba. El auditorio espera que la decisión se exprese de un modo que permita cumplir ciertos estándares epistémico-culturales y lingüístico-interpretativos. Que la decisión se

\footnotetext{
25 En el modelo de la prueba tasada aquello puede llevar, por ejemplo, a que el legislador establezca diferenciaciones entre testigos hábiles o inhábiles.

26 Wigmore (1931) p. 8.

27 Redondo (documento electrónico) y REDOndo (1999) pp. 149-163.
} 
escriba en un texto, que ese texto comunique las razones que justifican la decisión y, que el auditorio espere usar el texto para 'reconstruir' lo que pensó el juez y lo que pasó en el caso, son algunos de los criterios de calidad que tarde o temprano la decisión judicial debe cumplir. ${ }^{28}$

El carácter bidimensional de la valoración de la prueba supone que debe controlar la información usada en la decisión desde un punto de vista epistémico-cultural y, al mismo tiempo, debe posibilitar que la información considerada en la decisión se refleje en un texto de un modo tal que pueda usarse para satisfacer necesidades sociales diferentes a la justificación de la decisión. Este aspecto es importante para que la decisión judicial llegue a percibirse como justificada, pues la sociedad no espera solo que el texto sea satisfactorio en el espacio de lo jurídico, sino que además pueda ser usado como insumo para construir otros productos sociales como noticias, libros de historia, moralejas o películas de consumo masivo.

La demanda social por usar el texto que escribe el juez explica el control del estatus epistémico-cultural de la información analizada al tomar la decisión. Así, la información incluida en la decisión es plenamente dependiente de los conocimientos que se producen en otros entornos. En otras palabras: la sociedad reclama que el caso judicial se resuelva usando lo que se sabe en medicina, mecánica, antropología y psicología y que las razones que da el tribunal pueda ser transferidas a textos de historiografía, a una discusión política o a la noticia de un matutino, sin necesidad de hacer aclaraciones.

\subsection{Lo QUe PUEDE ESPERARSE DE los PL}

El estatus de las reglas de la lógica ha sido discutido por quienes cultivan la disciplina desde los trabajos de Von Wright. ${ }^{29}$ Sin entrar en este debate asumimos que se trata de reglas determinativas, de manera que ellas fijan un conjunto de razonamientos (formalmente) correctos; un conjunto de razonamientos posibles y, en algún sentido, definen la actividad misma de razonar. ${ }^{30}$

Al pensar en la lógica los juristas, habitualmente, adscriben una concepción psicologicista de la lógica clásica. Asumen entonces que 'la Lógica' es la ciencia del pensamiento formalmente correcto. ${ }^{31}$ En principio no hay razones para interpretar las expresiones 'reglas de la lógica' o 'principios de la lógica' que usan los textos legislativos como restringidas a la

28 Coloma (2011) pp. 75-97.

29 Von Wright (1979), Von Wright (1987), Von Wright (1998).

30 La 'fuerza constitutiva' de las reglas de la lógica, en tanto reglas constitutivas, permiten interpretar la acción de pensar. GuASTINI (1984) p. 308.

31 Alchourrón (1996) pp. 331-348. 
lógica clásica. ${ }^{32}$ Así, son aceptables reglas, por ejemplo, provenientes de lógicas no monotónicas $^{33}$; lógicas paraconsistentes o lógicas paracompletas. ${ }^{34}$

Las reglas de la lógica no suministran información sobre el mundo o sobre la realidad, sino que instituyen los límites del ejercicio del razonamiento. Esto significa que la lógica nos permite jugar el juego de pensar racionalmente; entendiendo la expresión 'racional' de un modo amplio, desformalizado e idiosincrásico. En este sentido, las reglas de la lógica nos permiten conocer, de antemano, qué movimientos o jugadas argumentativas pueden ser calificadas como correctas, posibles, incorrectas e imposibles en un determinado contexto social. Así, la lógica define la forma correcta de pensar y usar el lenguaje según el contexto.

Dado el estatus determinativo de las reglas de la lógica ellas se sitúan en un nivel diferente que la ciencia y la experiencia. La lógica no regula la introducción de información al proceso de análisis del caso, sino que vela por la corrección comunicativa de lo que puede ser pensado o imaginado dentro de una comunidad. De esta manera, el error del hablante o de quien argumenta desde el punto de vista de la lógica redunda en el fracaso del acto de habla, en el sinsentido del mensaje o, en la consideración de que se ha realizado un movimiento argumental equivocado.

Veamos dos ejemplos.

a) "Dorotea no sabe andar en bicicleta, por tanto pagó oportunamente los $\$ 1.000 .000$. pactados por el arrendamiento de la casa de veraneo".

La reacción del lector seguramente apuntará a que lo que se ha dicho es un sinsentido, no viniendo al caso calificarlo como verdadero o falso. La inferencia expresada en el texto carece de validez lógica, no porque la premisa utilizada lleve a la conclusión opuesta sino porque no hay suficiente conexión entre el antecedente y el consecuente (son independientes).

\footnotetext{
32 Por ejemplo, Hunter señala: Sobre las reglas de la lógica los juristas sostienen que ellas se componen de reglas como: "regla de la identidad, por la cual se asegura que una cosa solo puede ser lo que es y no otra; la regla de la (no) contradicción, por la que se entiende que una cosa no puede entenderse en dos dimensiones, como ser falsa o verdadera, al mismo tiempo; la regla del tercero excluido, la cual establece que entre dos proposiciones en la cual una afirma y otra niega, una de ellas debe ser verdadera; y, la regla de la razón suficiente, por la cual cualquier afirmación o proposición que acredite la existencia o no de un hecho debe estar fundamentada en una razón que la acredite suficientemente (...)”. HunTer (2012) pp. 243-251.

33 Una propuesta interesante de no reducir el papel de la lógica al que puede asociarse a la lógica clásica puede verse en LASO (2009) pp. 143-164.

34 Una lógica monotónica es aquella que postula que la inclusión de nuevas premisas en un razonamiento no puede reducir el conjunto de consecuencias. Esto es así porque las lógicas monotónicas trabajan bajo un supuesto de certeza sobre la verdad o falsedad de las premisas. En cambio, las lógicas no monotónicas permiten el razonamiento con incertidumbre, como la abducción. Una lógica es paraconsistente si ella acepta que se produzcan contradicciones, es decir, que viola el principio de no contracción de la lógica clásica en razón de que restringe o elimina el principio de separación. Una lógica es paracompleta si viola al menos una de las siguientes formulaciones del principio "tertium non datur": I. Dadas dos proposiciones contradictorias a y -a, una de ellas es verdadera. II. La proposición av - a es verdadera. DA Costa y LeWIN (1995) p. 189.
} 
b) "La droga fue encontrada en un sobre que estaba sobre la chimenea, entonces Antonio -quien es un romántico empedernido e infatigable lector de novelas policialesfue el autor del delito de tráfico ilícito de estupefacientes".

El destinatario (anterior a 1844) hubiese quedado perplejo con lo comunicado y habría reclamado que la inferencia realizada no es válida al no existir una estrecha relación entre ser un romántico empedernido e infatigable lector de novelas policiales con el hecho de esconder droga en un sobre sobre la chimenea. Sin embargo, el lector posterior podría encontrarle sentido a lo que se dice si es que estuviere en conocimiento que Edgar Allan Poe en su cuento "La carta robada» utiliza un ardid como el señalado. Por cierto, la inferencia podrá ser calificada de bastante débil dependiendo el contexto en que sea pronunciada. Así, por ejemplo, si se trata de juegos de ingenio la conexión planteada puede resultar más que suficiente para satisfacer las exigencias de relación. En cambio, si se trata de condenar a Antonio a pasar los próximos cinco años de su vida tras las rejas, debiera entenderse que no será una forma adecuada de argumentar, pues representa un salto inferencial no admisible habida cuenta de la existencia de un estándar de prueba exigente como lo es que no haya dudas razonables acerca de que la conducta existió y que esta fue realizada por el acusado.

De acuerdo a esta forma de comprensión los PL no son un límite a la libertad de justificación que condiciona el tipo de información sobre lo fáctico que resulta admisible expresar en la sentencia. ${ }^{35}$ Los PL cumplen funciones que operan en cuatro niveles: i) delimitan o definen aquello que es información de lo que es ruido; ii) permiten juzgar comparativamente ciertas las formas de organizar la información y, iii) orientan acerca de cómo debe utilizarse el contexto para completar lo implícito de un mensaje y iv) autorizan para utilizar un lenguaje no dubitativo en situaciones de incertidumbre.

En el primer nivel, la lógica posibilita comprender significados a través de estructuras sintácticas. La existencia de comunidades de hablantes que cotidianamente se comunican invisibiliza esta importante función que desempeña la lógica. Un buen ejemplo de esto es lo que ocurrió con el descubrimiento de la piedra Rosetta. El ruido ${ }^{36}$ que hasta ese entonces representaban los glifos egipcios muta en información. Esto sucede ya que la piedra Rosetta presenta tres versiones del mismo texto en distintas lenguas lo que hace posible a los estudiosos plantear una hipótesis sobre la organización de la lengua egipcia e iniciar el proceso de reconstrucción del significado de los ideogramas.

En el segundo nivel, la lógica opera como un conjunto de reglas que permiten, distinguir y comparar diferentes formas de organizar la información. El clásico ejemplo sobre

\footnotetext{
35 Si estuviésemos en lo cierto, convendrá tener a la vista otras variables normativas relativas a la construcción de lo probado y que no han sido formuladas hasta este momento, a pesar de que resultan claves para el éxito o fracaso en la motivación de las sentencias. Al respecto nos interesa poner sobre el tapete las ideas de carga de la prueba, estándar de prueba y algunos requisitos textuales del discurso fáctico de las sentencias.

36 El concepto de ruido está definido con precisión en las teorías de la información y comunicación. Aquí hemos usado el concepto en un sentido más informal. El ruido está formado por los datos que no podemos comprender porque desconocemos su significado. Así el ruido interfiere los procesos de comunicación y de análisis de la información.
} 
los frijoles que nos permite distinguir los esquemas deductivo, inductivo y abductivo es una manera muy clara de ilustrar el uso de lógica en esta dimensión.

\begin{tabular}{|c|c|c|c|}
\hline & \multicolumn{3}{|c|}{ Formas de razonamiento } \\
\hline & Deducción & Inducción & Abducción \\
\hline \multirow{3}{*}{ Secuencia } & $\begin{array}{l}\text { Todos los frijoles de la } \\
\text { bolsa azul son blancos }\end{array}$ & $\begin{array}{l}\text { Estos frijoles provienen } \\
\text { de la bolsa azul }\end{array}$ & $\begin{array}{l}\text { Todos los frijoles de la } \\
\text { bolsa azul son blancos }\end{array}$ \\
\hline & $\begin{array}{l}\text { Estos frijoles provienen } \\
\text { de la bolsa azul }\end{array}$ & $\begin{array}{l}\text { Estos frijoles son blan- } \\
\text { cos }\end{array}$ & $\begin{array}{l}\text { Estos frijoles son blan- } \\
\text { cos }\end{array}$ \\
\hline & $\begin{array}{l}\text { Estos frijoles son blan- } \\
\text { cos (conclusión) }\end{array}$ & $\begin{array}{l}\text { Todos los frijoles de la } \\
\text { bolsa azul son blancos } \\
\text { (conclusión) }\end{array}$ & $\begin{array}{l}\text { Estos frijoles provienen } \\
\text { de la bolsa azul (con- } \\
\text { clusión) }\end{array}$ \\
\hline $\begin{array}{l}\text { Condiciones } \\
\text { para el uso de } \\
\text { la conclusión, } \\
\text { en contextos } \\
\text { de toma de } \\
\text { decisión }\end{array}$ & $\begin{array}{l}\text { Inexistentes. La estruc- } \\
\text { tura por sí sola legitima } \\
\text { el uso de la conclusión }\end{array}$ & $\begin{array}{l}\text { La estimación de la } \\
\text { probabilidad (acierto/ } \\
\text { error) legitima el uso } \\
\text { de la conclusión }\end{array}$ & $\begin{array}{l}\text { La aceptación de la co- } \\
\text { rrección de conclusión } \\
\text { (conjetura) depende } \\
\text { de la superación de un } \\
\text { estándar de prueba }\end{array}$ \\
\hline
\end{tabular}

El ejemplo permite observar que, en esta dimensión, los PL no son un límite a la información que es usada, sino solo una restricción a la 'forma de la conclusión' que puede derivarse a partir de cada estructura de pensamiento. Ahora bien, en este nivel la lógica solo posibilita comparar en abstracto el alcance o generalidad de la conclusión de cada razonamiento. La lógica solo nos dice que los razonamientos deductivo y abductivo conducen a una conclusión particular, mientras que el inductivo finaliza con una conclusión universal. La lógica no es un límite a la elección de cuál es la forma de razonar más conveniente para afrontar un problema específico. Esta elección es una cuestión heurística que depende, por un lado, del tipo de problema que debe resolverse y del tipo de solución al cual debe arribarse y; por otro, de cuáles son los patrones de legitimación de un razonamiento dentro de una comunidad determinada.

En el tercer nivel la lógica se hace cargo de que el lenguaje requiere hacer uso de lo implícito. En cuanto a lo implícito, la lógica orienta al hablante acerca de cómo debe hacerse cargo de las expectativas que lo que se dice puede generar en un auditorio.

Veamos un ejemplo de una declaración hipotética de un testigo en un caso de lesiones o violencia intrafamiliar: «Pericles estaba furioso con Aspasia y sacó un cuchillo». Son muchas las respuestas que, de un modo inferencial, el lector puede dar a la pregunta: ¿Qué quería hacer Pericles con el cuchillo? Una respuesta según la cual Pericles sacó un cuchillo para cortar un trozo de carne que ella le había sido servido en su plato es posible, pero defrauda nuestras expectativas sobre la intención de Pericles, mientras que una respuesta del tipo Pericles sacó un cuchillo para amenazar y herir a Aspasia podría satisfacer mejor nuestras expectativas. Dejando entre paréntesis cualquier otra información, ambas respuestas no pueden ser calificadas como verdaderas o falsas, ni tampoco se puede afirmar que ellas sean lógicas o ilógicas. Lo único que puede afirmarse es quien sabe que la narración tratará sobre 
un caso de lesiones o de violencia doméstica 'espera' una secuencia de eventos en donde "hombre agrede, a veces con un arma, a una mujer" y, entonces, esa expectativa condiciona todos los juicios sobre la coherencia, completitud y capacidad narrativa de la declaración del testigo.

En el cuarto nivel la lógica se hace cargo de las exigencias del uso correcto de expresiones tales como "está probado" o de la formulación de descripciones sin que sean acompañadas de indicadores de incertidumbre. El mensaje transmitido en una sentencia judicial no admite ser debilitado con el uso de términos dubitativos, como «quizás» o «probablemente», aun cuando ello sea usual en otros contextos. ${ }^{37}$ En otras palabras, para declarar que X mató a Y, o que Fulano celebró un contrato con Mengano se precisa que el hablante asuma la superación de un determinado estándar de prueba y si aquello no es tenido en consideración -hay otras explicaciones alternativas con buenas credenciales como para haber sido aceptadas- se podrá objetar que se vulneraron los PL al haber dado por probado un determinado acontecimiento.

Los ejemplos demuestran que los razonamientos cotidianos de las personas y los razonamientos de los jueces no son guiados por la lógica clásica. Para modelar el pensamiento informal es necesario transitar desde las exigencias de la lógica aristotélica hacia estructuras de argumentación que reflejen cómo las personas reflexionan y toman decisiones con información incompleta, incorrecta e incierta. ${ }^{38}$

\subsection{LO QUE PUEDE ESPERARSE DE LOS CCA}

Lo que llamamos ciencia es un conjunto heterogéneo de discursos. En general, calificamos como 'científicos' a aquellos discursos que son formulados por grupos de expertos que gozan de prestigio social y que se circunscriben en ciertas áreas del conocimiento. ${ }^{39} \mathrm{La}$ delimitación del conjunto de discursos científicos es borrosa (fuzzy), porque no es sencillo determinar qué discursos son 'verdadera ciencia' en un momento y lugar determinados. ${ }^{40}$ Probablemente, en lugar de intentar encontrar una cualidad inmanente y no relacional que defina qué es ciencia y qué no lo es, resulte más fructífero determinar quiénes son considerados como científicos en una comunidad determinada, para luego observar los discursos que ese grupo de personas usa para producir y fijar sus descubrimientos. ${ }^{41}$

Los científicos investigan fenómenos que, en muchas ocasiones, resultan desconcertantes e inexplicables de acuerdo al sentido común o a las ME. Los científicos reducen este desconcierto creando un discurso que llamamos 'ciencia'. Este discurso explica los fenómenos estudiados mediante su reconceptualización e inserción en un sistema de significados dentro del cual, dadas sus particulares circunstancias, cada fenómeno se subsume en leyes

\footnotetext{
37 Véase Austin (1989) p. 105 y Toulmin (2007) p. 75.

38 VAn Eemeren y Grootendorst (2002).

39 Bourdieu (1984), Bourdieu (2003).

40 El problema de la demarcación de aquello que es reconocido como científico ha sido abordado extensamente en el sistema norteamericano, a propósito de la admisibilidad del testimonio de los peritos. Además de la revisión de la discusión en torno a la regla 702 de las Federal Rules of Evidence, puede verse un panorama general en HAACK (2008).

41 Kuhn (1994), Parodi (2008).
} 
generales. ${ }^{42}$ Así, dentro del discurso científico, fenómenos dispares y aparentemente desconectados entre sí; como la caída de una manzana, el movimiento orbital de los planetas y el ascenso de las mareas se integran y unifican como manifestaciones de una única ley científica. ${ }^{43}$

Los saberes descubiertos o elaborados por los científicos son llamados 'conocimientos científicos' para distinguirlos cualitativamente de otros saberes en razón de quien accedió a ellos; de la forma en que fueron adquiridos o del modo en que fueron fijados. No todos los conocimientos determinados a través del método científico se encuentran afianzados. Algunos conocimientos científicos tienen un estatus provisional en la medida en que son el resultado de investigaciones de frontera, mientras que otros saberes tienen un estatus de alta consolidación y, entonces, sustentan avances tecnológicos que permiten su aplicación en la vida social. Un conocimiento se ha afianzado, consolidado o asentado cuando es incuestionable en un sentido sincrónico. ${ }^{44}$ El estatus de indiscutibilidad es una consecuencia del consenso y supone, por regla general, el sometimiento a un método de trabajo es funcional a evitar el error que implica el uso de procesos informales de procesamiento de datos. ${ }^{45}$

El conocimiento que fija el discurso científico es, para los legos en ciencia, un conjunto de verdades de dicto y no de facto. La diferencia estriba en la forma en que se adquiere el conocimiento. Un conocimiento es de dicto, cuando no es accesible directamente sin la intermediación de un marco cultural. Quienes no sabemos cómo comprobar o refutar las teorías científicas solo podemos confiar en lo que 'dicen' los científicos. Quienes somos legos en ciencia recibimos el conocimiento científico a través de un conjunto difuso de patrones culturales y, por ello, tenemos poco (o ningún acceso), a las herramientas que permitirían cuestionar el conocimiento. El conocimiento de facto, en cambio, se hace depender de la confianza que el sujeto tiene en su capacidad sensorial para percibir los fenómenos que suceden en su entorno. ${ }^{46}$

De acuerdo a la tradicional distinción entre ciencia y técnica, el concepto de ciencia está indisolublemente ligado a los de conocimiento y descubrimiento. Estos vínculos definen el trabajo científico: es ciencia aquella tarea (discurso) que persigue obtener nuevos saberes sobre la realidad aumentando el margen de certidumbre sobre ella. En principio, no es un rasgo definitorio del saber científico su 'usabilidad' para resolver problemas prácticos, porque su foco principal del trabajo científico está en obtener conocimiento predicativo ('saber qué') ${ }^{47}$. Las dificultades de la vida diaria como la seguridad, la velocidad, la movili-

\footnotetext{
42 Torretti (2012) pp. 84-85.

43 En este caso, la teoría de la gravitación universal de la física newtoniana.

44 El número de planetas que componía el sistema solar hasta 2006 era nueve. Luego de la Asamblea General de la Unión Astronómica Internacional, el número se redujo a ocho por la supresión de Plutón. En un sentido diacrónico, este conocimiento sigue sujeto a revisión, pues nadie podría afirmar la absoluta imposibilidad que el número ascienda a doce (o se reduzca a siete) según se modifique la definición de planeta.

45 Según William Groove y Paul Meehl, la aplicación de métodos mecánicos (que suponen uso de algoritmos) son invariablemente mejores que los informales que se hacen depender en parte importante de la subjetividad de quienes toman decisiones. Grove y Meenl (1996) pp. 319 -320 (especialmente).

46 ECO (2011).

47 Medina (1995) p. 180.
} 
dad, la intercomunicación, el almacenamiento y la identificación no son problemas típicamente científicos, sino que problemas tecnológicos y de diseño. La preocupación principal de los técnicos es entonces resolver problemas usando el conocimiento ya domesticado por los científicos ${ }^{48}$. Así, ellos no están interesados en el conocimiento mismo ni en la consecuente reducción de la incertidumbre, sino que en la 'usabilidad' de los saberes para modificar la realidad (natural o social). Los técnicos se ocupan de arribar a un conocimiento operativo ('saber cómo').

La clásica distinción entre ciencia y tecnología ha sido superada porque el modo de trabajar de los científicos es cada vez más tecnocientífico y porque muchos filósofos han aceptado que la ciencia no solo describe la realidad, sino que la interviene. ${ }^{49}$ Un enfoque que puede ser útil para nuestros fines lo proporciona Bunge (1969), para quien es característico de la tecnología "contar con instrucciones para realizar un número finito de actos en un orden dado y con un objetivo determinado". Estas instrucciones son normas que se basan en leyes científicas y cuyo propósito es regular el desempeño de quien ejecuta la técnica para garantizar así un resultado consistente en el tiempo. La idea de instrucción de Bunge es muy ilustrativa sobre lo que esperamos los abogados -como legos en ciencia y en tecnología- de un perito (médico, bioquímico, mecánico, bombero, etc.). Queremos tener seguridad sobre la consistencia de un resultado en el tiempo y queremos saber cómo es posible resguardar esa seguridad. A los abogados nos interesa tanto el conocimiento predicativo como el operativo. La idea de Bunge permite comprender mejor uno de los significados del adjetivo 'afianzado' que las disposiciones normativas usan para calificar los 'conocimientos científicos'. Este afianzamiento exigido por el legislador podría ser entendido como un proceso de tecnologización de la ciencia. Si así fuese entendido, un CCA es un saber que encontrando su origen en descubrimientos científicos ha sido operacionalizado de forma tal que contamos con reglas (la tecnología) que nos permiten regular qué acciones debemos realizar para conseguir resultados consistentes en el tiempo.

Sin profundizar en el problema de juzgar resultados periciales parcialmente incompatibles, creemos que dirimir controversias entre peritajes de dos ciencias o disciplinas, entre escuelas rivales de una misma ciencia o, simplemente entre dos peritos, exige realizar distinciones. Siguiendo a Latour ${ }^{50}$ es útil diferenciar entre peritajes que son producidos preeminentemente por la intervención de artefactos, aparatos e instrumentos; y peritajes en donde los resultados son fuertemente dependientes de la intervención de un agente humano. Una distinción así es útil porque permite entender mejor el significado de la expresión 'científicamente afianzado' al exigir distinguir el modo en que se consolida un resultado científico-tecnológico y a través de la forma en que se ha obtenido.

La distinción implica diferenciar los resultados producidos principalmente por artefactos, instrumentos o máquinas (como el test de $\mathrm{ADN}$ ); los producidos por la concurrencia de aparatos y de agentes humanos (como la autopsia) los elaborados principalmente por

\footnotetext{
48 No podemos profundizar en la caracterización de los científicos y los tecnólogos. Sin embargo, nos parece necesario prevenir al lector de la imagen romántica del científico como un teórico que describe la realidad sin interferir en ella. MEDina (1995).

49 Por todos, Hacking (1983).

50 Latour (1994).
} 
la intervención de un agente (como una pericia psiquiátrica). Intuitivamente, sin experticia en las tecnologías respectivas, nos parece que el $\mathrm{ADN}$ es una prueba más fuerte que las otras. Esa intuición no está determinada solo por el valor científico o el prestigio de la bioquímica como ciencia. El sustento de la validez y la confiabilidad de test de ADN, se encuentran en que es una prueba biológica que cuyo resultado es obtenido usando 'la mejor tecnología disponible'; donde la expresión 'la mejor tecnología disponible' significa, aproximadamente, atender al menos a cuatro factores: i) la capacidad de repetir el test en igualdad de condiciones, ii) la baja tasa de error de resultados, iii) la intervención de aparatos, artefactos e instrumentos de última generación diseñados especialmente para ejecutar el examen y, iv) la existencia de mecanismos de control de calidad en la ejecución del procedimiento. ${ }^{51}$ Algunos de esos cuatros factores fallan en el peritaje planimétrico y más todavía, en el test psicológico: por eso confiamos menos en ellos ${ }^{52}$.

Evidentemente, la regla de entender como más afianzado al conocimiento científicotecnológico obtenido con 'la mejor tecnología disponible' no ayuda a resolver los conflictos entre resultados periciales generados solo por agentes humanos. Aquí, el margen de error es mayor y la carga de justificación del resultado se desplaza desde la máquina a la persona del perito. Es necesario entonces entender que afianzado significa arraigado en una red de conocimientos y en una comunidad de investigadores. Por ello, no vendrá al caso utilizar los factores recién indicados para dar cuenta de la mejor tecnología, sino que será necesario ponderar los siguientes: i) el desempeño precedente del perito; ii) la experticia y actualización de sus conocimientos tecnológicos; iii) la densidad interpretativa de los resultados, iv) la ética de trabajo previo y v) el reconocimiento académico del trabajo previo ${ }^{53}$.

Este escenario calza de lleno con las ciencias sociales y humanas, en donde los resultados no están intermediados por el uso de instrumentos y artefactos. Es necesario, entonces, atender a dos dificultades respecto a las que vale la pena detenerse un momento: El primer problema de los peritajes en ciencias como la sociología, el trabajo social, la literatura, la antropología y en algunas áreas de la lingüística es que la distinción entre saberes de dicto y de facto se debilita ${ }^{54}$ y eso nos lleva a pensar que los peritajes nos hablan 'es algo que ya sabemos'. ${ }^{55}$ La percepción de 'creer saber algo' consiste entonces, en pensar que ciertos saberes de dicto son, en realidad, saberes de facto.

\footnotetext{
51 De este modo, en ciencias cuyos resultados son dependientes casi por completo del uso de aparatos e instrumentos (como la informática, la bioquímica y la mecánica de suelos) el asunto es juzgar qué perito usó el equipo más moderno y siguió las reglas de actuación más rigurosas.

52 Estos factores podrían entenderse como máximas de la experiencia sobre la elección entre dos resultados científico-tecnológicos.

53 Este listado no es taxativo ni debe ser interpretado como un orden de prelación.

54 Esto afecta también a los conocimientos privados del juez que no resulten reformulables en clave de conocimientos de dicto, pues no se han afianzado en el marco cultural que domina la comunidad.

55 A diferencia de ello, cuando un juez dice, por ejemplo, 'el peritaje de ADN confirma que Pedro es el padre de Juan', en realidad lo que se quiere decir es 'confío en que el perito haya realizado bien su trabajo y por ello creo que está confirmado que Pedro es el padre de Juan’. Para los abogados, los saberes científicos y tecnológicos son de dicto, porque su producción y fijación se realiza a través de textos y discursos en los que confiamos aunque no entendemos cabalmente.
} 
Así, creemos saber de estilos literarios porque leemos novelas como El Barón Rampante o El Quijote; creemos saber sobre medición de la pobreza porque la vemos en la televisión o la hemos vivido; creemos saber sobre multiculturalidad y la situación de los migrantes porque hemos conversado ocasionalmente con ellos o porque los observamos mientras viajamos en el transporte público; creemos saber sobre los mapuche porque leemos los diarios de circulación nacional y creemos saber sobre la educación de los hijos y sobre las buenas (y las malas) dinámicas familiares porque las tenemos o las hemos sufrido; como todos sabemos, se podría continuar la lista con un largo etcétera.

El segundo problema de estas ciencias es que no es posible entenderlas únicamente a partir de los resultados que proporciona su tecnología. Ya que todas ellas tienen en común el estudiar el comportamiento humano ( $v$.gr. las prácticas sociales), los resultados científicos deben juzgarse afianzados cuando ellos: i) logran densidad interpretativa; ii) adoptan una tecnología que garantiza representación estadística o, iii) combinan ambos estándares. Logra densidad interpretativa la investigación que consigue que los participantes de una práctica social perciban que los resultados del trabajo científico representan o describen adecuadamente lo que ellos hacen. ${ }^{56}$ Por otro lado, aquellas investigaciones que no profundizan en los significados, pueden ajustarse al estándar estadístico de la representación el cual, por regla general, determina la confiabilidad y validez de una investigación social.

No es posible afirmar que una investigación social o humana representativa es siempre mejor que una interpretativa o viceversa. Por eso parece razonable priorizar, en muchos contextos judiciales, a los peritajes que balanceen ambos procedimientos científicos y, si ello no ocurre, es necesario recurrir a criterios que están fuera del objeto de estudio y de la tecnología: i) Experiencia, actualización del perito; ii) Desempeño precedente del perito; iii) Capacidad de la pericia de contextualizar una práctica en profundidad; iv) Capacidad de la pericia para describir una población o muestra en detalle. ${ }^{57}$

De acuerdo a las ideas precedentes podemos enunciar cuatro reglas de decisión entre estos conocimientos científico-tecnológicos (afianzados). La primera regla dice que debe preferirse el conocimiento producido con la mejor tecnología disponible en un momento dado. La segunda regla dice que ante igualdad de condiciones tecnológicas debe preferirse al conocimiento que tiene mayor sustento en la comunidad científica de referencia. La tercera regla dice que la tasa de error condiciona la elección entre un resultado producido por un artefacto y un resultado producido por un humano. La cuarta regla dice que a igualdad de todos los factores anteriores el juez tiene discrecionalidad para decidir entre los dos resultados científicos.

Es claro que los conocimientos no afianzados científicamente, es decir, aquellos que no son susceptibles de planificación técnica no constituyen un límite a la valoración de la prueba en el modelo de la sana crítica. La razón es sencilla. Carecemos de procedimientos (instrumentos, protocolos de acción, comunidad científica) que nos permitan planificar la

\footnotetext{
56 La única forma de juzgar la densidad interpretativa de la investigación sobre una práctica social es interrogando a un participante de dicha práctica sobre el grado de autoidentificación con los resultados de la investigación. Winch (1972; 1994a; 1994b).

57 Este listado no es taxativo y no debe ser interpretado como un orden de prelación.
} 
obtención de resultados consistentes en el tiempo, porque desconocemos la técnica que se necesita para reducir la tasa de error a niveles que nos permitan tomar decisiones confiables. Ahora bien, el hecho de que no contar con procesos científico-tecnológicos no es una razón que justifique que el juez carezca de límites para valorar la prueba científica no afianzada $^{58}$

\subsection{Lo QUE PUEDE ESPERARSE DE LAS ME}

A diferencia de lo que ocurre con las pretensiones de universalidad de los CCA, las generalizaciones que surgen de la experiencia poseen marcados rasgos de localidad e idiosincrasia. ${ }^{59}$ Las ME son útiles para tomar decisiones, porque el conocimiento consolidado dentro de un grupo humano en un momento y lugar determinado, permite comprender, explicar o reconstruir el comportamiento de los miembros de ese grupo. En virtud de la experiencia es posible empatizar y atribuir intenciones a quienes se encuentren en situaciones equiparables a las vividas por otros integrantes del grupo. ${ }^{60}$ Sabemos que las personas se comportan regularmente de cierta manera y que siguen un conjunto de patrones que podemos llamar genéricamente como 'cultura'. Así, frente a un comportamiento diferente al acostumbrado, el cambio debe explicarse dentro de la cultura para estar justificado. En este sentido, las ME permiten justificar por qué la acción de una persona es o no extraña, sorpresiva, irrazonable o contraria al sentido común. ${ }^{61}$

Una adecuada comprensión de las ME exige distinguir entre experiencias individuales y colectivas, como también entre conocimientos públicos y privados. La experiencia individual es aquella que le ha ocurrido a un sujeto o a un grupo reducido de sujetos, existiendo buenas razones para pensar que, bajo las mismas condiciones, no es previsible la misma vivencia genere el mismo aprendizaje en un gran número de individuos. Ganar el premio mayor de la Lotería, ser alcanzado por un rayo, sobrevivir en un naufragio probablemente se experimentarán de manera bastante distinta y los aprendizajes serán diferentes para cada sujeto.

\footnotetext{
58 Los criterios de racionalidad de este tipo de decisiones probatorias serán abordados en un trabajo futuro.

59 No obstante, las raíces de las máximas de la experiencia se radicarían en sociedades culturalmente homogéneas (como pudo haber sido el caso de Alemania de fines del siglo XIX) y en un contexto en que la comprensión del razonamiento de los jueces se encontraba estrechamente comprometida con la idea de razonamiento silogístico. TARUfFo (2006) pp. 126 y 127.

${ }^{60}$ Von Wright (1987), Von Wright (1998), Von Wright (1980).

${ }_{61}$ Pese a que las conclusiones que arrojan las ME y el sentido común suelen ser coincidentes se trata de conceptos diferentes. Garth Fletcher ha indicado, por ejemplo, que el sentido común considera: a) "Asunciones necesarias para mantener una visión inteligible y explicable del mundo". Este sería el caso de que «el mundo existe independientemente de nuestras percepciones», que "somos la misma persona cada día», etc.; b) "Máximas culturales o de conocimientos compartidos". Este sería el caso de proverbios que guían el comportamiento como «mira antes de saltar» o que ayudan a explicar principios sicológicos como es el caso de «Dios los cría y el diablo los junta»; y c) "Maneras coincidentes de pensar". Estas refieren a ciertas heurísticas compartidas para enfrentar determinadas situaciones. FletCher (1984) pp. 203-213. Las dos primeras categorías presentan niveles de coincidencia solo parciales (hay una conexión ocasional con las experiencias y sobre todo con el carácter público de estas) y en la tercera no se da propiamente una relación ya que el sentido común no refiere a generalizaciones acerca de cómo ocurren las cosas, sino que alude a una cierta forma de operar (es el caso del habitual reclamo de ¡debes usar el sentido común!). Véase también TARuffo (2001) p. 669.
} 
La experiencia colectiva es la que ha experimentado un número elevado de sujetos de la comunidad, siendo especialmente determinante para calificarla como tal la circunstancia de que existan buenas razones para pensar que ante las mismas condiciones otros individuos vivirán la misma experiencia y aprenderán más o menos lo mismo que quienes les antecedieron. La colectividad o individualidad de las experiencias es graduable y depende de las prácticas sociales de cada comunidad. Jugar u observar cómo se juega un partido de fútbol; asistir diariamente a la escuela; subir una montaña son experiencias colectivas porque esas vivencias pueden reproducirse en condiciones más o menos similares.

El conocimiento es público cuando el aprendizaje que surge de la(s) experiencia(s) se encuentra difundido entre los miembros de la comunidad y su valor o significado puede ser abiertamente comunicado. El conocimiento es privado cuando la difusión del aprendizaje es escasa o cuando la sociedad cuenta con reglas que impiden que ese conocimiento sea expresado públicamente.

Los casos a considerar, entonces, son cuatro: a) experiencias colectivas y conocimiento público; b) experiencias individuales y conocimiento público; c) experiencias colectivas y conocimiento privado; y d) experiencias individuales y conocimiento privado. Las ME, stricto sensu, son aquellas directrices que se construyen a partir de experiencias colectivas y de conocimiento público. ${ }^{62}$ El carácter colectivo de la experiencia permite considerar que las directrices son pautas de inferencia que no se agotan en los casos singulares. El carácter público, a su vez, permite invocar un grado de inercia argumentativa que incide en no tener que justificar el uso de la generalización en caso de debate. ${ }^{63}$

Las generalizaciones que se infieren a partir de experiencias individuales y de conocimiento público, en principio no deberían considerarse como ME, aunque ellas podrían fundar excepciones ante la forma estándar de comprender el comportamiento de las personas. Así, al valorar la conducta de un piloto de carreras en un accidente, la regla de inferencia proviene de una experiencia individual, ya que la vivencia de conducir automóviles de carrera en competiciones deportivas solo la viven un número reducido de sujetos. $\mathrm{Al}$ mismo tiempo, el conocimiento es parcialmente público, pues los que observamos la práctica del deporte sabemos (o creemos saber) lo que significa la velocidad y podemos imaginar un fragmento de la experiencia de conducir a trescientos kilómetros por hora.

Las experiencias individuales de público conocimiento también son reconducibles al esquema del conocimiento de dicto. Ellas constituyen generalizaciones que se construyen para explicar el comportamiento humano y que son comunicadas no por una experiencia directa sino por la transferencia desde otros. Comparten, además, la naturaleza de cono-

\footnotetext{
${ }^{62}$ Friedrich Stein dice que las ME "son definiciones o juicios hipotéticos de contenido general, desligados de los hechos concretos que se juzgan en el proceso, procedentes de la experiencia, pero independientes de los casos particulares de cuya observación se han inducido y que, por encima de esos casos, pretenden tener validez para otros nuevos", véase STEIN (1988) p. 27.

63 Las reglas que podrían usarse por ejemplo, para valorar la conducta violenta de los espectadores de un partido de fútbol o para juzgar la imprudencia de quienes sin conocimiento escalan una montaña un fin de semana, provienen de experiencias colectivas y de conocimiento público que hacen comprensible pensar que un espectador pueda insultar verbalmente al árbitro frente a un error o que un excursionista amateur corre bastantes riesgos al caminar por la montaña sin el equipo ni el entrenamiento adecuados.
} 
cimientos validados culturalmente, aunque a diferencia de lo que ocurre con la ciencia la participación activa en el discurso que las configura no depende del dominio disciplinario sino de la existencia de alguna clase de vínculos familiares, territoriales, religiosos, etcétera. El prestigio por tanto resultará discutible por parte de quienes no compartan tales vínculos.

El efecto de exclusión de la categoría de las ME asociada a la experiencia individual se explica mejor si se considera que el carácter no repetitivo de la experiencia dificulta enormemente la forma de comprender el rol que cumplieron las variables contextuales que pudieron haber incidido en cómo el sujeto reaccionó ante un determinado estímulo. Marc Bloch a propósito del interés de los estrategas militares por extraer y comunicar aprendizajes a partir de una gran batalla ocurrida en el pasado enfatiza que para evitar errores debieran identificarse todos los factores del pasado y del presente (red de caminos, acceso a mapas, acceso a provisiones, etc.) que incidirán en que el futuro podría ser muy distinto al pasado. La interpretación de la experiencia pasa por considerar que si uno quiere extraer lecciones del pasado y anticipar repeticiones en el futuro debiera agregarse una cláusula de la forma "por lo demás todo igual». ${ }^{64}$ Esta indicación, por cierto, debilita el carácter general que es esperable de las ME.

Las experiencias colectivas pero cuyo conocimiento es privado no generan ME porque no son generalizables. Lo que de ellas puede extraerse tampoco es apto para sustentar razonamientos con un alto grado de inercia argumentativa, porque el conocimiento no puede ser controvertido y, por ello, su introducción en la valoración de la prueba está sujeta a cumplir con las cargas de argumentación. Algunas de las reglas que podrían usarse para valorar el comportamiento de los ejecutivos en prácticas de negociación empresarial, por ejemplo, en torno al uso de información privilegiada, son casos de este tipo de reglas. En la medida que no se cuente con datos fiables acerca de qué dimensión de la experiencia es realmente colectiva, es posible que deba invocarse el sentido común para juzgar el comportamiento. Es decir habría que decir algo así como: "el comportamiento esperable en el caso X era A".

Los aprendizajes que se derivan de experiencias individuales y conocimientos privados no pueden ser usados para juzgar el comportamiento de otros individuos de la comunidad, pues de ellas no pueden extraerse generalizaciones. Las reglas que regulan las experiencias de este tipo son las que dan forma a los asuntos que son tabúes o secretos dentro de una sociedad y, aunque, de hecho, pueden gozar de inercia argumentativa, ella no es susceptible de ser controvertida. La experiencia de Neil Armstrong en la Luna, en la medida que se mantiene en la esfera privada y no es problematizada, constituye un ejemplo de ellas.

\section{ENTRE LA SUJECIÓN A LOS PL, LAS ME Y LOS CCA Y LA LIBERTAD PARA DESENTENDERSE DE ELLOS}

\subsection{INTRODUCCIÓN}

Para lo que viene nos será útil parafrasear una afirmación formulada por el juez Learned Hand hace poco más de un siglo respecto del conocimiento pericial: «Nadie ne-

${ }^{64}$ BLOCH (2008) pp. 44-45. 
gará que los jueces debieran usar los CCA [-podemos añadir, las ME y los PL-], donde sea que ayuden a aclarar disputas. El único problema es cómo podrían hacerlo de la mejor manera» ${ }^{65}$. Tomarse en serio lo recién dicho implica hacerse cargo de la interrogante de cuándo son realmente aplicables los CCA, las ME y los PL -en términos de inhibir las preferencias subjetivas de los jueces acerca de cómo valorar la prueba disponible- y cómo resolver las tensiones que ocasionalmente se presentan entre los CCA y las ME.

\subsection{LOS espacios no CUbiertos POR los CCA, LAS ME y los PL}

Según hemos visto los PL, por una parte, y los CCA y ME, por la otra, cumplen distintas funciones en el contexto de la valoración de la prueba. Los PL dirimen formas correctas (o aceptables) de comunicarse e interactuar en determinados ámbitos. Aquello lo logran a través de la diferenciación entre información (que como tal es potencialmente útil) y ruido (que como tal, resulta inútil); como también, validando estructuras argumentales a las cuales se puede recurrir para establecer relaciones entre la prueba disponible y los enunciados planteados bajo la expectativa de que sean reconocidos como hechos probados. Los PL constituyen, de esta manera, una importante salvaguarda lingüístico-interpretativa ante el sinsentido, ante el absurdo, ante interpretaciones desafortunadas de lo que está implícito en un texto, como también ante piezas textuales débilmente relacionadas. Los PL, en cambio, no constituyen cortapisas ante lo falso o lo carente de plausibilidad.

En cuanto reglas determinativas, los PL no establecen una delimitación exhaustiva de lo que válidamente puede ser planteado y de lo que no vendría al caso. Si bien es cierto, los PL prohíben algunas movidas lingüístico-interpretativas, los hablantes contarán con un amplísimo marco de lo que puede ser dicho, incluso si es falso, poco interesante o escasamente inteligente. ${ }^{66}$ Los PL suponen, entonces, que los jueces cuando dan por probados ciertos hechos respetan ciertas formas lingüístico-interpretativas que llevan a que se entienda que usan correctamente las palabras. En ese sentido, los PL suponen formas de relación entre enunciados y una cierta intensidad de dicha relación, lo que da espacio que los PL presentan una forma de vinculación con los mecanismos de gestión de la incertidumbre (estándares de prueba y carga de la prueba).

Las ME y los CCA establecen generalizaciones acerca de cómo es o cómo funciona el mundo. ${ }^{67}$ Ambos permiten ir más allá de lo que directamente ofrecen los datos disponibles. Las diferencias radican en el tipo de comunidad que hace que las respectivas generalizaciones se consideren validadas y, consecuencialmente, los métodos para su producción y eliminación. Los CCA y las ME funcionan como mecanismos de introducción y clasificación de información sobre el evento juzgado. Así, una afirmación como por ejemplo: "el peritaje de ADN registró un 99,999\% de probabilidades de que la sangre encontrada en el arma perte-

\footnotetext{
65 Hand (1901) p. 40.

${ }^{66}$ En esa línea de pensamiento, es interesante observar que el estudio de la argumentación, desde hace algún tiempo, se ha desplazado el estudio de las falacias desde "argumentos que parecen válidos pero que en realidad no lo son" a su comprensión como movimientos inadecuados del discurso argumentativo que son aceptados por un auditorio en determinadas condiciones. VAn EEMEREn y Houtlosser (2008) p. 37.

67 En términos más técnicos la pregunta a formular adoptaría una forma más compleja, como por ejemplo, ¿cómo es válido representar aquello que entendemos como la realidad?
} 
necía al acusado" puede ser admitida como integrante del discurso sobre el evento juzgado en razón de que se sustenta en un CCA. Algo similar ocurre con las ME: la afirmación: "es habitual entre los padres pidan a la enfermeras que pongan aros en las orejas de sus hijas dentro de los primeros días después del nacimiento" puede ser considera como admisible (en referencia a un grupo social determinado), en virtud la existencia de conocimientos compartidos entre todos los miembros del grupo y del conocimiento adquirido por el juzgador en virtud de su experiencia de vida en esa comunidad.

No ocurre lo mismo tratándose de la calificación de la información producida a partir de otras generalizaciones. La afirmación "la conjunción entre Venus y Marte causa una tendencia violenta en el acusado dado que es de signo Escorpión" seguramente será desechada del discurso sobre el evento que juzga en un proceso en razón de su baja tasa de aceptación por parte de los miembros de la comunidad (es riesgoso guiar nuestra conducta usando dicha información). La confianza o la fiabilidad de los miembros de la comunidad sobre lo que se dice de la realidad es el criterio de marginación de información y no su dudoso estatus científico. Por ello, la información producida por peritajes realizados de acuerdo a estándares de ciencias 'blandas' es habitualmente desplazada por información privada del juez o que es conocimiento compartido de los miembros de la comunidad, incluso si ella es errónea ${ }^{68}$.

En razón de lo expresado, los CCA y las ME operan como reglas técnicas para introducir datos útiles para el juzgamiento del evento controvertido. En tanto mecanismos de calificación de información como inservible, funcionan como reglas ideales que permitan al juzgador construir un .juicio de desconfianza sobre esta. De esta manera, la reacción ante un uso incorrecto de los CCA o de las ME se traduce en dudas acerca de la calidad de los datos e implícitamente, en un ejercicio de valoración de los riesgos que conlleva su uso ${ }^{69}$.

Veamos un par de ejemplos:

Se entiende como CCA el enunciado "los metales se dilatan cuando se les aplica calor". Una generalización como la indicada permite excluir un determinado objeto de la categoría metales si es que habiéndosele aplicado calor no se ha dilatado.

Se entiende como una ME que "las madres están dispuestas a realizar muchos sacrificios si aquello redunda en mejores condiciones de vida para sus hijos”. Una generalización como la indicada provocará dudas respecto de la imparcialidad de una madre cuando enfrenta una acusación respecto de su hijo, salvo que haya datos adicionales según los cuales nos enfrentaríamos a una situación de no aplicación de la ME (por ejemplo, esta madre en el pasado ha demostrado que no quiere a su hijo).

Al igual de lo que ocurre con los PL, tanto los CCA y las ME constituyen sistemas incompletos de generalizaciones que dan cuenta de la conducta humana, esto es habrá situaciones en que múltiples respuestas no admiten ser jerarquizadas como más o como menos posible.

\footnotetext{
68 Hay una relación afectiva con los conocimientos previos y es difícil desplazarlos.

${ }^{69}$ Usamos la información de Wikileaks sin ser científica. Tampoco está validada por la experiencia. No tenemos una regla ideal que nos permita excluirla.
} 
Veamos un ejemplo hipotético de incumplimiento de contrato o de despido injustificado: Jerónimo acudió al edificio de la calle Magnolia 25 y regresó sin haber realizado la limpieza en los departamentos 401 y 402, según era su obligación. Entre otras alternativas podrían plantearse cualquiera de las siguientes explicaciones: 1) Nadie le abrió las puertas; 2) En el inmueble no estaban los implementos para realizar el aseo; 3) Jerónimo y su jefe tuvieron un altercado, siendo despedido antes que realizara la limpieza; y 4) Alguien ya había realizado el aseo.

Desde un punto de vista lógico todas las inferencias resultan igualmente aceptables, ya que satisfacen en la misma medida las exigencias para ser consideradas como causa de que Jerónimo no haya realizado el aseo, pese a que acudió al lugar en que debía ejecutarlo. Debemos, entonces, explorar qué opción es la que resultaría más plausible, dada la manera en que ocurren ordinariamente las cosas. Para tales efectos los conocimientos científicamente afianzados son inservibles, pues no se dispone de generalizaciones que den cuenta de una situación como la que habría vivido Jerónimo (no son útiles para fortalecer o debilitar las opciones disponibles). En una sociedad como la nuestra, las ME de poco servirían ya que las hipótesis disponibles resultan todas plausibles. Seguramente lo que resultará determinante a fin de cuentas son el uso de una serie de heurísticas con las que habitualmente enfrentamos estas situaciones.

Cuando no existen otras fuentes de generalizaciones legitimadas para establecer preferencias entre explicaciones potenciales, se pasa a operar en un espacio en que se reconoce libertad a los jueces en la valoración de la prueba. El asunto parece sencillo, pero hay razones para pensar que podría ser uno de los aspectos que inciden en el relativo fracaso de la sana crítica. Los jueces evitan asumir la responsabilidad propia de valorar libremente la prueba, sobre todo cuando sus elecciones no demuestran ser muy superiores a las que podrían alcanzarse lanzando una moneda al aire. Para tales efectos, es previsible que los jueces recurran a formas de construcción de conocimientos que presentan escaso valor epistémicocultural, ${ }^{70}$ pero que se disfrazarán con expresiones tales como uso del sentido común o peor aún, invocando que las conclusiones son evidentes cuando no lo son.

\subsection{Relaciones ordenadoras entre los enunciados extraíbles desde los PL, LOS CCA Y LAS ME}

La ciencia y la experiencia son discursos acerca del mundo o realidad, mientras que la lógica es un metadiscurso: un discurso cuyo objeto principal es otro discurso. La preocupación de los PL está puesta en la estructura o en la forma del mensaje y la preocupación de los CCA y ME, en los significados o en el contenido del mensaje. Esta constatación lleva a pensar que las tensiones entre las generalizaciones emanadas de estas distintas categorías solo debieran presentarse entre las dos primeras. Esto, sin embargo, sería una conclusión apresurada y constituye el primer asunto que abordaremos en este acápite.

La estructura del discurso y el significado de las palabras se encuentran en una relación de interdependencia, según la cual la mayor cobertura reconocida a una de tales di-

${ }^{70}$ Este sería el caso de lo que Tverski y Kahneman han identificado como las heurísticas de la disponibilidad, representatividad y anclaje. 
mensiones implica restricciones para la otra. Los PL al fijar las condiciones requeridas para el uso correcto del lenguaje en el contexto de la valoración de la prueba establecen indirectamente qué es lo que puede extraerse desde los CCA y las ME. Al contrario, los significados que imponen los CCA y las ME a los discursos pueden implicar nuevos desafíos para los PL: estos últimos deberán hacerse cargo de estos fallos y si no lo hacen arriesgan ser desplazados por nuevas formas de comunicación. Una expresión de esto último se observa en la necesidad de que la lógica se haga cargo de que nuestras representaciones de la realidad son falibles (o si se prefiere, probabilísticas) lo cual implica el establecimiento de estándares de prueba que representan estrategias para poder hablar autorizadamente de lo que se encuentra probado, en escenarios marcados por un mayor o menor nivel de incertidumbre.

En términos metafóricos, los PL fijan los movimientos posibles que pueden hacerse con las palabras (la sintaxis); por su parte, los CCA y las ME determinan la imagen que se permite asociar a las palabras (aquello que cumple con las exigencias impuestas por la semántica). Una primacía del movimiento por sobre la imagen implicará una serie de beneficios lógicos del discurso que es generado en sede judicial, como lo sería un aumento en la coherencia o la relevancia de lo que se dice. A su vez, una primacía de la imagen por sobre el movimiento implicará que el significado como compromiso con la realidad gana en nitidez, aun cuando ello irá acompañado de un deterioro en las conexiones sintácticas, como lo sería el uso del «entonces» o del «porque». ${ }^{71}$

Veamos un ejemplo. Para la determinación de la paternidad o de la maternidad de una persona respecto de otra el examen de ADN ha traído consigo un aumento de la precisión (imagen) y con ello una reordenación de las relaciones que pueden establecerse entre el contenido (lo epistémico-cultural) y la estructura (lo lingüístico-interpretativo). En este escenario, los CCA suministran un mecanismo muy potente para la determinación de «lo que es» relegando al juicio de coherencia a un papel muy secundario. Si el examen de ADN arroja como conclusión que el demandado es el padre de un menor de edad, la manera en que aquello encaja con las otras piezas de información disponibles pierde interés. De esta manera, por ejemplo, la sentencia no deberá hacerse cargo de si existe o no un parecido físico entre padre e hijo, del tipo de relación que hubo entre el padre y madre biológico, etc. A contrario, antes de los exámenes de ADN o de grupo sanguíneo resultaba imprescindible una sintaxis que estableciera conexiones fuertes entre distintas piezas de información disponible, esto es declaraciones de testigos, cartas de amor, conducta previa del presunto padre con el menor de edad, etc. En ese sentido si cualquiera de las piezas de información no calzaba con el resto constituía un argumento poderoso para entender que la paternidad no estaba probada.

Una serie de decisiones del legislador, junto a la manera en que se configura la cultura jurídica constituyen razones para entender que prima facie habría una primacía de los PL

\footnotetext{
71 Esto, por cierto, tiene una semejanza clara con el principio de «incertidumbre» de Heisenberg que en sus versiones simplificadas sostiene que la precisión en la determinación de la posición de una partícula se obtiene a costa de una pérdida en la determinación de cuál es su movimiento lineal (y viceversa). Véase HaWKING (2003) pp. $42-43$.
} 
por sobre los CCA y las ME. ${ }^{72}$ En rigor se trata de una decisión y no de la primacía que per se pudiera reconocerse a la forma sobre el contenido. ${ }^{73}$ En la cultura de jueces y abogados se ha instalado, por su parte, la idea de que la fundamentación de la sentencia constituye una exigencia clave para los efectos de entender que la decisión judicial no es arbitraria y que el texto que se presente debe articular adecuadamente los distintos insumos que se han tenido en cuenta para la toma de la decisión. ${ }^{74}$

Despejado el punto anterior, es preciso abocarse ahora a las tensiones que pueden presentarse entre los CCA y las ME. El problema evidentemente es distinto al anterior ya que no se trata de generalizaciones que se ubican en distintos niveles, sino que compiten en lo que hemos llamado dimensión epistémico-cultural. Es fácil advertir que los CCA están mejor situados en el ámbito de lo eminentemente epistémico y las $\mathrm{ME}$, en el nivel preferentemente cultural.

El prestigio de los saberes emanados de la ciencia, nos provee de buenas razones para entender que superan a los de las ME. La división del trabajo lleva a que lo que dicen los especialistas sea más valorado que lo que puede señalar cualquier miembro de la comunidad sin conocimientos especializados. ${ }^{75}$ Lo expresado no debe llevar a pensar que viene al caso establecer una forma única de relaciones ordenadoras, ya que no todos los CCA cuentan con el mismo nivel de legitimación, ni todas las ME cuentan con el mismo nivel de adhesión. Una solución promisoria a este problema pasa por agrupar a las diferentes ciencias o disciplinas científicas según el tipo de explicación con las que prioritariamente trabajen. Aunque no es una solución exenta de dificultades, pensamos que esta estrategia de análisis podría ayudar a clarificar, por un lado, las similitudes y diferencias que median entre el trabajo de un físico, de un médico y de un psicólogo y, por otro; las tensiones entre ciertos tipos de conocimientos científicos y las ME.

La revisión de los tipos de explicación científica nos permite pensar mejor su relación con las ME, entendida como el conjunto de conocimientos sobre el funcionamiento social y del entorno que se adquieren por la vida en comunidad. Las ME compiten con los CCA en las explicaciones teleológicas (funcionales e intencionales). Juegan un rol de menor cobertura en las explicaciones causales estadísticas y cumplen un rol escasamente significa-

72 Así, por ejemplo, en el artículo 342 del Código Procesal Penal se dice que: "La sentencia definitiva contendrá: (...) c) La exposición clara, lógica y completa de cada uno de los hechos y circunstancias que se dieren por probados, fueren ellos favorables o desfavorables al acusado, y de la valoración de los medios de prueba que fundamentaren dichas conclusiones de acuerdo con lo dispuesto en el artículo 297".

A su vez, el aludido artículo 297 señala que “...El tribunal deberá hacerse cargo en su fundamentación de toda la prueba producida, incluso de aquélla que hubiere desestimado, indicando en tal caso las razones que hubiere tenido en cuenta para hacerlo. La valoración de la prueba en la sentencia requerirá el señalamiento del o de los medios de prueba mediante los cuales se dieren por acreditados cada uno de los hechos y circunstancias que se dieren por probados. Esta fundamentación deberá permitir la reproducción del razonamiento utilizado para alcanzar las conclusiones a que llegare la sentencia".

73 De hecho hay buenas razones para pensar que en el discurso científico, por ejemplo, las observaciones ponen en entredicho a las teorías explicativas aun cuando no se cuente con una buena explicación alternativa.

74 Esto es lo que probablemente lleva a Joel González a añadir a la fundamentación de las sentencias como elemento constitutivo de la sana crítica. GONZÁlEZ (2006) pp. 102-105.

75 Naturalmente, el problema del prestigio del conocimiento no se vincula con el uso. Que un conocimiento sea prestigioso no significa que sea usado de forma cotidiana por los miembros de la comunidad o por los jueces. 
tivo en el razonamiento científico causal nomológico-deductivo. De este modo, la forma en que se integran ciencia y experiencia (y de resolver sus conflictos) es diferente según sea el tipo de explicación científica que modele la forma de pensar de los científicos. En el caso de explicaciones teleológicas-intencionales las ME cumplen un papel importante en la determinación de la intención del agente, por lo cual, la integración entre ciencia y experiencia es fuerte y, podría suceder el caso que ciertos conocimientos científicos se vean derrotados por la experiencia (por ejemplo, resistencia a la validación de test psicológicos extranjeros a la realidad nacional). El nivel de integración entre experiencia y ciencia en las explicaciones teleológico-funcionales es menor y el conocimiento científico goza de privilegios relativos, porque las ME siguen siendo útiles para comprender la globalidad del fenómeno desde una perspectiva holística. A su vez, tratándose de disciplinas científicas que trabajan principalmente con explicaciones causales, la integración entre ciencia y experiencia es mínima, pues ella solo se reduce a colmar los espacios de "silencio" que dejan las leyes estadísticas.

Un último asunto del que vale la pena dar cuenta para establecer relaciones ordenadoras se produce en razón de que al interior de una misma categoría pueden presentarse tensiones, esto es, existen CCA que compiten entre sí y ME rivales. Con esto no nos estamos refiriendo al problema que representa la determinación de si una cierta disciplina o método cuenta con credenciales como para ser considerada como científica, ni el estatus de afianzado que se reconoce a un cierto conocimiento, ni tampoco a si se duda sobre el estatus de ME que puede otorgarse a una cierta generalización extraíble desde el ámbito de la cultura. El asunto apunta a que la fiabilidad de un cierto método o saber puede ser diferente al momento de hacer predicciones o reconstrucciones de la realidad. En el caso de los CCA el problema no es difícil de resolver ya que las disciplinas suelen hacerse cargo de determinar el riesgo de errar cuando se aplica un determinado procedimiento. Los jueces debieran, entonces, hacer diferencias entre una fiabilidad del $99,99 \%$ y una de un $80 \%$ aun cuando no estén familiarizados con el lenguaje de la probabilidad. El asunto parece más complicado cuando se trata de ME rivales, no quedando muchas otras opciones que vayan más allá del análisis de la adhesión cultural frente a cada una de ellas y, sobre todo, del ejercicio de argumentación que es esperable de parte de los jueces en cuanto a que la primacía de una por sobre la otra corresponde a un mejor calce con el caso al cual se está enfrentando. Así, las cosas la posibilidad de hacer uso de los CCA y las ME no es un obstáculo para que los jueces de todas formas lleven a cabo un ejercicio de fundamentación en un entorno de valoración de la prueba conforme a la sana crítica.

\section{CONCLUSIONES}

1. El principal acierto del modelo la sana crítica lo constituye su opción por la coexistencia de espacios de deber y de libertad. Los jueces, en ocasiones, deberán someterse a los PL, CCA y ME; y en otras, se moverán con libertad si las generalizaciones disponibles no determinen lo que válidamente puede concluirse de la prueba rendida. Esta propiedad ha redundado en la comprensión de la sana crítica como un modelo de valoración racional de la prueba. 
2. El modelo de la sana crítica definido por el legislador es conceptualmente incompleto. La sujeción a los PL, CCA y ME que ordena el legislador es solo una definición ostensiva de lo que es la valoración racional y razonable de los medios de prueba, dejando una serie de asuntos abiertos respecto a las propiedades que la definen. ${ }^{76}$

3. El principal problema que aqueja a la sana crítica se relaciona con su escasa operatividad en cuanto modelo que reenvía a los jueces a sistemas externos de producción de conocimiento o de legitimación de discursos. Dicho fenómeno es consecuencia de la falta de precisión conceptual de lo que se está refiriendo cuando se hace mención a los PL, CCA y ME. Asimismo, la incorporación de los PL, CCA y ME es poco explícita respecto a quiénes están obligando y cuál es el contenido de dicha obligación. Más aún, no están suficientemente resueltos otros problemas asociados, como lo son las tensiones entre distintas generalizaciones disponibles o la distinta fuerza que puede reconocérseles para dar respuesta a un caso concreto. Así, las decisiones probatorias de jueces especializados no parece diferir de las que tomaría una persona mínimamente sensata.

4. Los PL definen la información que debe ser valorada y, al mismo tiempo, controlan el discurso judicial que establece relaciones entre los medios de prueba y lo que se da por probado. Su función no se relaciona con la determinación de lo verdadero o lo falso sino con las formas correctas de hablar en el contexto del proceso judicial.

5. Los CCA permiten introducir información sobre los eventos juzgados y posibilitan al juez hacer uso de procedimientos y saberes asentados en comunidades disciplinarias socialmente reconocidas. Al igual que las ME su función es asegurar que el razonamiento probatorio sea deferente con generalizaciones validadas desde una perspectiva epistémicocultural.

6. Las ME presentan un fuerte compromiso con lo que constituyen formas de comprensión de la vida social asentadas a nivel local. El carácter no institucionalizado de las ME hace útil distinguir dos criterios de organización del conocimiento vivencial: por una parte, la publicidad de la información conduce a diferenciar conocimientos públicos y privados y; por otro lado, según el grado de alteridad de la experiencia que produce el conocimiento distinguimos experiencias comunes e individuales. Estas dos distinciones nos permiten distinguir cuatro tipos de conocimientos vivenciales: i) público-común; ii) público-individual; iii) privado-común y, iv) privado-individual. El primero es una ME en sentido pleno. El último, en cambio, es un conocimiento privado que es desconocido para otras personas y no cuenta con credenciales como para exigir su utilización en los juicios. Las otras dos categorías son más dudosas. Por una parte, el carácter público del conocimiento que puede acompañar una experiencia individual suele ser asimilado por lo que llamamos sentido común, mientras que el conocimiento privado que emerge a partir de una experiencia común, cuenta con el apoyo de constituir una vivencia que se repite, aunque culturalmente no se consolide aprendizaje alguno.

7. Los CCA y las ME pueden converger o divergir, según conduzcan (o no) a tomar la misma decisión. Si convergen, la ciencia y la experiencia justifican en un mismo sentido la

${ }^{76}$ Muchos de las de las reglas que definen estos asuntos están reguladas por la cultura jurídica ComanducCi (1999). 
decisión evaluativa sobre los medios de prueba, con lo que no existe tensión que haya que enfrentar. El problema se produce cuando la decisión que surge de la ciencia y de la experiencia es divergente. Los CCA poseen una carga emotiva positiva que no tiene el conocimiento que surge de las ME. Esta 'aura' de prestigio que protege al discurso científico, sin embargo, no es una razón apabullante para preferir fundar la decisión en razones científicas por sobre las razones que provienen de la experiencia. La dificultad para controlar la validez de los CCA por parte de los jueces constituye una objeción ante esta forma de jerarquización.

8. En espacios en los que los PL, ME y CCA son insuficientes para orientar el ejercicio de valoración de la prueba, es importante que los jueces asuman su responsabilidad de valorarla. En lugar de recurrir a heurísticas que disfrazan formas de razonamiento que con frecuencia son incorrectos, los jueces deberían comunicar el ejercicio deliberativo que se hace cargo de la incertidumbre.

9. Dos dimensiones que no fueron abordadas debieran ser tratadas en estudios futuros. La primera de ellas se refiere la percepción de los jueces chilenos sobre qué significa valorar la prueba y el significado y la función que pueden asignarse a los PL, CCA y ME. La segunda trata sobre la elaboración de un análisis del impacto que podría tener promulgar normas que regulen el proceso de valoración y sus limitaciones, en el marco de la sana crítica.

\section{BIBLIOGRAFÍA CITADA}

Alchourrón, Carlos (1996): "On Law and Logic", Ratio Juris, vol. 9 N 4: pp. 331-348.

Anderson, Terence, Schum, David y Twining, William (2005): Analisys of Evidence (New York, Cambridge University Press, segunda edición).

Apostel, Léo (2007): “¿Cuál es la fuerza de un argumento? Algunos problemas y sugerencias", Revista Praxis Filosófica, No 25: pp. 129-137.

Austin, J. L. (1989): “Otras mentes”, en Austin, J. L., Ensayos filosóficos (Madrid, Alianza) pp. 87-116.

BLOCH, Marc (2008): Historia e historiadores (Madrid, Akal).

Bourdieu, Pierre (1984): Homo academicus (Paris, Les Éditions de Minuit).

Bourdieu, Pierre (2003): El oficio de científico. Ciencia de la ciencia y reflexividad (Barcelona, Ed. Anagrama).

Bunge, Mario (1969): La investigación cientifica: su estrategia y su filosofía (Barcelona, Ariel).

Comanducci, Paolo (1999): Razonamiento jurídico. Elementos para un modelo (México, DF.: Fontamara).

Coloma, Rodrigo (2011): "Las buenas y las malas historias. Criterios de validación del discurso de los hechos en sentencias judiciales”, en Cuestiones Contemporáneas de Teoría Analítica. (Madrid, Marcial Pons) pp. 75-97.

Coloma, Rodrigo (2012): "La caída del argumento de autoridad y el ascenso de la sana crítica”, Revista de Derecho (Valdivia), vol. XXV No 2: pp. 207-228.

Da Costa, N.; Lewin R. A. (1995): "Lógica Paraconsistente”, en Alchourrón, C.; Orayen, R. (comps.), "Lógica”, Enciclopedia Iberoamericana de Filosofía, vol. 7: p. 189. 
Eco, Umberto (2011): Confesiones de un joven novelista (Barcelona, Lumen).

Fletcher, G. (1984): "Psychology and Common Sense", American Psychologist, vol. 39 No 3: pp. 203-213.

GonZÁlez, Joel: "La fundamentación de las sentencias y la sana crítica", Revista Chilena de Derecho, vol. 33, No 1: pp. 93-107.

Grove, William; Meent, Paul (1996): “Comparative Efficiency of Informal (Subjective, Impressionistic) and Formal (Mechanical, Algorithmic) Prediction Procedures: The Clinical-Statistical Controversy", Psychology, Public Policy, and Law, 2: pp. 293-323.

Guastini, Riccardo (1984): “Teoría de las reglas constitutivas: Searle, Ross, Carcaterra”, Revista de Ciencias Sociales Universidad de Valparaiso: pp. 297-316.

HaAck, Susan (2007): "Entangled in the Bramble-Bush", en Haack, S., Defending science within reason: between scientism and cynicism (New York, Prometheus Books) pp. 233264.

HaAcK, Susan (2008): "Verdad y justicia, investigación y abogacía, ciencia y ley", en Haack, S., Ciencia, Sociedad y Cultura (Santiago, Ediciones Diego Portales) pp. 281-304.

Hacking, Ian (1983): Representing and Intervenin (Cambridge, Cambridge University Press).

Hand, Learned (1901): "Historical and Practical Considerations regarding Expert Testimony", Harvard Law Review, vol. 15 N$^{\circ}$ 1: pp. 40-58.

Hawking, Stephen (2003): El universo en una cáscara de nuez (Barcelona, Crítica, novena edición).

Huber, Peter (2011): Galileo's Revenge. Junk Science in the Courtroom (New York, BasicBooks, reimpresión).

Hunter, Iván (2012): "Control judicial de las reglas de la sana crítica”, Revista de Derecho de la Universidad Austral de Chile, Vol. XXV, No 1: pp. 243-251.

Kunn, Th. (1994): La estructura de las revoluciones cientificas (Madrid, Fondo de Cultura Económica, primera edición, decimosexta reimpresión).

Medina, Manuel (1995): “Tecnología y filosofía: más allá de los prejuicios epistemológicos y Humanistas", Isegoría, No12: pp. 180-196.

Laso, Jaime (2009): "Lógica y sana crítica", Revista Chilena de Derecho, vol. $36 \mathrm{~N}^{\circ} 1$ : pp.143-164.

Latour, Bruno (1994): "On Technical medition-Philosophy, Sociology, Genealogy", Commmon Knowledge, vol. 3, No 2: pp. 29-63.

Parodi, Giovanni (2008): "Géneros académicos y géneros profesionales: Delimitaciones y puntos de encuentro en el Corpus PUCV-2006”. En Parodi, Giovanni (ed.), Género académico y géneros profesionales: accesos discursivos para saber y hacer (Valparaíso, Ediciones Universitarias de Valparaíso, Pontificia Universidad Católica de Valparaíso) pp. 75-96.

Redondo, Cristina. (1999): "La justificación de las decisiones judiciales", Revista Isegoría, $\mathrm{N}^{\circ}$ 21: pp. 149-163.

Redondo, Cristina: "Sobre la justificación de la sentencia judicial” Disponible en: http:// www.fcje.org.es/wp-content/uploads/file/jornada21/1_REDONDO.pdf [Última visita: 4 de septiembre de 2013]. 
Schauer, F. (2003): "Profiles, probabilities and stereotypes", The Belknap Press of Harvard University Press, Cambridge \& London: pp. 55-78.

STEIN, Friedrich (1988): El conocimiento privado del juez (Bogotá, Editorial Temis).

TARufFo, Michele (2001): "Senso comune, esperienza e scienza nel ragionamento del giudice", Rivista trimestrale di Diritto e Procedura Civile: pp. 665-695.

TARuffo, Michele (2006): "Sentido común, experiencia y ciencia en el razonamiento del juez”, en Taruffo, Michele, Sobre las fronteras. Escritos sobre la justicia civil (Temis) 323 pp.

TORRETTI, Roberto (2012): Inventar para entender (Santiago, Editorial Universidad Diego Portales).

Toulmin, Stephen (2007): Los usos de la argumentación (Barcelona, Península).

Tversky, Amos y Kahneman, Daniel (2012): "El juicio bajo incertidumbre: heurísticas y sesgos”, en Kahneman, Daniel. Pensar rápido, pensar despacio (Buenos Aires, Debate).

Van Eemeren, Frans y Grootendorst, Rob (2002): Argumentación, comunicación y falacias. Una perspectiva pragma-dialéctica (Santiago, Ediciones Universidad Católica de Chile).

Van Eemeren, F., Houtlosser, P. (2008): "Más sobre falacias como descarrilamientos de maniobras estratégicas: el caso de tu quoque”, en Santibáñez, C., Marafioti, R. (eds.), De las falacias: argumentación y comunicación (Buenos Aires, Biblos) pp. 37 - 51.

Von Wright, G. H (1987): Explicación y comprensión (Madrid, Alianza).

Von Wright, G. H (1998): Un ensayo de lógica deóntica y la teoría general de la acción (México D. F., Universidad Autónoma de México).

Von Wright, G. H. (1979): Norma y acción, Una investigación lógica (Madrid, Tecnos).

Von Wright, G. H. (1980): "El determinismo y el estudio del hombre", en Hiintika, Jaakko; MacIntyre, Alasdair; Winch, Peter y otros, Ensayos sobre explicación y comprensión. Contribuciones a la filosofía de las ciencias humanas y sociales (Madrid, Alianza).

Von Wright, G. H. (1993): "Images of science and forms of rationality", en Von Wright, G. H., The tree of knowledge and other essays (Leiden - New York, E. J. Brill) p. 172.

WALDRON, Jeremy (1996): "Minority cultures and the cosmopolitan alternative", en Kymlicka, Will (ed.), The rights of minority cultures (Oxford, Oxford University Press) pp. 105-108.

Wigmore, John (1931): The principles of judicial proof or the process of proof as given by logic, psychology, and general experience and illustrated in judicial trials (Boston, Little, Brown, and Company, second edition).

Winch, Peter (1972): Ciencia social y filosofía, (Buenos Aires, Amorrortu).

WINCH, Peter (1994a), "Naturaleza y convención", en Id., Comprender una sociedad primitiva (Barcelona, Paidós) pp. 111-143.

WINCH, Peter (1994b), "Comprender una sociedad primitiva”, en Id., Comprender una sociedad primitiva (Barcelona, Paidós) pp. 111-143. 


\section{JURISPRUDENCIA CITADA}

Ministerio Público con Lorena Maldonado (2010): Primera Sala del Tribunal de Juicio Oral en lo Penal de Talca (Lesiones menos graves), RIT N 156-2010.

Robynson Gómez Noa (2009): Corte de Apelaciones de Valdivia, 14 de mayo de 2009 (Apelación de medida de protección), Rol N 103-2009 FAM.

Ministerio Público con Inti Ramírez Basic (2007): Tercer Tribunal de Juicio Oral en lo Penal de Santiago, 3 de abril de 2007 (Robo con violencia) RIT No 28-2007.

Ministerio Publico con Nicole Parra (2012): Corte de Apelaciones de Santiago, 12 de diciembre de 2012 (Recurso de Nulidad), Rol N³112-2012 REF.

Ministerio Público con Mans (2012): Corte de Apelaciones de Valparaíso, 1 de junio de 2012 (Recurso de Nulidad), Rol N 539-2012. 
